Cahiers $d u$ MONDE RUSSE

\section{Cahiers du monde russe}

Russie - Empire russe - Union soviétique et États indépendants

$43 / 4 \mid 2002$

Intellectuels et intelligentsia

\title{
Delphine Bechtel, La Renaissance culturelle juive en Europe centrale et orientale, 1897-1930
}

\section{Boris Czerny}

\section{(2) OpenEdition}

\section{Journals}

Édition électronique

URL : https://journals.openedition.org/monderusse/4056

DOI : 10.4000/monderusse.4056

ISSN : $1777-5388$

\section{Éditeur}

Éditions de l'EHESS

\section{Édition imprimée}

Date de publication : 30 décembre 2002

Pagination : 793-795

ISBN : 2-7132-1796-2

ISSN : $1252-6576$

Référence électronique

Boris Czerny, «Delphine Bechtel, La Renaissance culturelle juive en Europe centrale et orientale, 1897-1930 », Cahiers du monde russe [En ligne], 43/4 | 2002, mis en ligne le 18 juin 2009, consulté le 03 septembre 2022. URL : http://journals.openedition.org/monderusse/4056 ; DOl : https://doi.org/ 10.4000/monderusse.4056

Ce document a été généré automatiquement le 3 septembre 2022.

Tous droits réservés 


\title{
Delphine Bechtel, La Renaissance culturelle juive en Europe centrale et orientale, $1897-1930$
}

\author{
Boris Czerny
}

\section{RÉFÉRENCE}

Delphine BECHTEL, La Renaissance culturelle juive en Europe centrale et orientale, 1897-1930. Langue, littérature et construction nationale. Paris, Belin, 2002, 319 p., carte

1 Le titre du livre annonce une approche synthétique des cultures juives en Europe centrale et orientale et des différents types de projets nationaux. L'incipit, constitué d'une phrase de Simon Bernfeld (p. 2) sur l'oscillation entre l'Est et l'Ouest du peuple juif tout au long de son histoire, définit la structure de l'ouvrage qui, comme le suggèrent les nombreux titres et sous-titres, donne une large place à une organisation spéculaire. Ainsi le choix des intitulés des paragraphes et leur contenu, par exemple « la vie intellectuelle en exil» (p. 206) et «réponse des intellectuels juifs allemands» (p. 209), témoignent d'une volonté d'opposer les grands mouvements qui parcoururent les deux hémisphères européens du monde juif à la fin du XIX et au début du XX⿳⺈冂大 siècle, afin de mieux cerner leurs zones de coïncidences et, in fine, leurs tensions communes vers la renaissance juive. Cette expression, comme le rappelle Delphine Bechtel, fut utilisée par Martin Buber (p.138) dans une revue au nom très significatif, Ost und West en 1901, à la veille d'une vague de « dissimilation » chez les juifs allemands (p. 69, 150).

2 L'étude de la renaissance culturelle juive du début $\mathrm{du} \mathrm{xx}^{\mathrm{e}}$ siècle à travers les contacts et les échanges littéraires inter-ashkénazes est concentrée sur le développement des littératures juives en allemand, hébreu, yiddish, qui « en l'espace de quelques années passèrent en accéléré par toutes les révolutions littéraires qui avaient pris des décennies dans toutes les littératures européennes » (p. 72). Dès les premières pages, les dates de 
1897 (année de fondation du Bund et du parti sioniste), 1908 (Congrès de Czernowitz au cours duquel furent proclamées l'égalité des droits pour la langue yiddish par rapport à l'hébreu et la volonté d'unification du peuple juif), 1917, puis la montée du nazisme en Allemagne à partir de 1924, sont autant de repères qui fixent avec fermeté le cadre temporel. Cependant la place principale est accordée à l'histoire des idées et à l'évolution de la création littéraire ${ }^{1}$ (écriture romanesque, poésie, essais, carnets de voyages) jusqu’à la prose expressionniste des écrivains russes émigrés dans les années 1920 à Berlin, avec, entre autres, Leyb Kvitko dont Delphine Bechtel donne une lecture inédite du recueil Les Peaux du Rio Grande (1928). La présence « dissimulée » du " grand-père » de la littérature yiddish, Mendele Moykher Seforim, dans la nouvelle Buchmendel (1929) (p. 195)de Stefan Zweig, donne à l'auteur l'occasion de souligner l'existence de nombreuses passerelles entre l'Est et l'Ouest.

La notion d'interdépendance spatiale et temporelle des deux branches maîtresses de la culture ashkénaze est étendue aux différentes formes d'expression écrite. En de maintes occasions, grâce à l'étude précise de documents inédits, D. Bechtel surmonte les clichés sur l'utilisation politique du yiddish, de l'hébreu et de l'allemand, à travers "l'engouement pour la langue yiddish, motivé par des engagements politiques très divers, et instrumentalisé pour les justifier» (p.119), ainsi que parl'évolution du sionisme politique vers la renaissance juive (p.65). Cette approche permet d'éviter les a priori qui sont chassés avec une belle constance. Les pages 56 à 61 , consacrées à la démarche volontariste qui prévalut dans la création du yiddish littéraire, sont caractéristiques d'une écriture donnant la préférence à des ajustements successifs qui sont le produit de la confrontation des opinions des nombreux acteurs de la renaissance culturelle juive. Par exemple, dans le sous-chapitre consacré au " travail des linguistes ", à une considération générale sur la philologie succèdent un rappel du contexte historicolinguistique puis un éclairage inédit sur le congrès de Czernowitz et les positions des différents participants par rapport au yiddish et à l'hébreu. En conclusion, l'auteur souligne la dimension humaine de la création de la nation juive et apporte des arguments en faveur d'une étude globale et variée de la culture juive, considérée comme un corps bicéphale dont chaque tête ne cessait de scruter sur le visage de l'autre des traces de sa propre identité ou originalité. À ce titre, Le visage du Juif (1920) d'Arnold Zweig est, selon nous, une des expressions littéraires les plus abouties de l'interrogation des juifs allemands sur leur assimilation et la recherche d'un ressourcement spirituel dans « le portrait vivant du frère de l'Est » (p. 161).

Les allers et retours entre l'Est et l'Ouest pour suivre l'évolution de la situation linguistique relèvent d'une approche comparatiste qui permet d'apprécier les pérégrinations des images dans le temps et l'espace ainsi que leurs évolutions en fonction des vagues d'assimilation ou de dissimilation. Les études sur les traductions littéraires du yiddish en allemand (p.119-133) débouchent sur une analyse très intéressante de l'« usage social de la littérature yiddish » qui est à relier avec la création d'une représentation mythique du shtetl ${ }^{2}$ en Europe de l'Ouest et d'un Orient situé en Asie (p. 164), en Palestine ou au plus profond d'un inconscient collectif chez Kafka et Else Lasker-Schüler (p. 176-194). La définition du «territoire » de la nation juive et de ses nombreuses variantes [nation de culture (p.29), entité culturelle (p.62), nation linguistique selon les principes de $\operatorname{Herder}^{3}$ (p. 75), collectivité biologique et spirituelle (p.123), corps viril (p.147), communauté d'âme (p. 99) et d'exil (p.153), etc.], de son centre et de ses confins en tant que lieu de ressourcement spirituel, ainsi que l'exposé des voyages de ceux qui firent fonction de «médiateurs" entre les cultures, occupent, à 
juste titre, une place essentielle. Aussi pouvons-nous regretter les lacunes d'une carte sur laquelle ne figure pas la Suisse où résidèrent de nombreux bundistes russes. De même, les lieux où se retrouvèrent les Ostjuden et Westjuden, et surtout les différents noms des villes qui furent l'objet de batailles politiques et linguistiques auraient dû être indiqués. Cela aurait aussi permis du même coup de définir la notion de « langue juive ».

5 La renaissance de la culture juive est appréhendée par l'auteur dans toute la pluralité des représentations collectives et individuelles d'un judaïsme conçu comme une confrontation exégétique en mouvement permanent. De ce point de vue, le livre est profondément, structurellement juif. Sa lecture incite à établir d'autres liens, en particulier avec la littérature juive de langue russe. Il est un signe d'espoir pour une nouvelle renaissance.

\section{NOTES}

1. Les termes de « littérature » et « littéraire » sont à prendre dans leur acception (russe) la plus large possible : la production écrite.

2. Les pages (119-140) sur le shtetl en tant qu'espace fantasmatique d'abord honni puis sublimé par les juifs de l'Ouest, et la définition de la modernité juive entre ces deux espaces que furent au $\mathrm{XX}^{\mathrm{e}}$ siècle le bourg de l'Est européen et la ville occidentale (p. 155), pourraient servir de base à une étude sur la relativité des représentations dites folkloriques.

3. Sur l'influence de Herder en Europe orientale, voir Anne-Marie Thiesse, La création des identités nationales, Europe XVIII ${ }^{e}-\mathrm{XX}^{e}$ siècle, Paris, Seuil, 1999. 